NBS MONOGRAPH 62

MAY 11963

\title{
Testing of Metal \\ Volumetric Standards
}

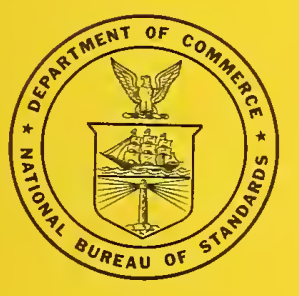

U.S. DEPARTMENT OF COMMERCE

NATIONAL BUREAU OF STANDARDS 


\section{THE NATIONAL BUREAU OF STANDARDS}

\section{Functions and Activities}

The functions of the National Bureau of Standards are set forth in the Act of Congress, March 3, 1901, as amended by Congress in Public Law 619, 1950. These include the development and maintenance of the national standards of measurement and the provision of means and methods for making measurements consistent with these standards; the determination of physical constants and properties of materials; the development of methods and instruments for testing materials, devices, and structures; advisory services to government agencies on scientific and technical problems; invention and development of devices to serve special needs of the Government; and the development of standard practices, codes, and specifications. The work includes basic and applied research, development, engineering, instrumentation, testing, evaluation, calibration services, and various consultation and information services. Research projects are also performed for other government agencies when the work relates to and supplements the basic program of the Bureau or when the Bureau's unique competence is required. The scope of activities is suggested by the listing of divisions and sections on the inside of the back cover.

\section{Publications}

The results of the Bureau's research are published either in the Bureau's own series of publications or in the journals of professional and scientific societies. The Bureau itself publishes three periodicals available from the Government Printing Office: The Journal of Research, published in four separate sections, presents complete scientific and technical papers; the Technical News Bulletin presents summary and preliminary reports on work in progress; and CRPL Ionospheric Predictions provides data for determining the best frequencies to use for radio communications throughout the world. There are also five series of nonperiodical publications: Monographs, Applied Mathematics Series, Handbooks, Miscellaneous Publications, and Technical Notes.

A complete listing of the Bureau's publications can be found in National Bureau of Standards Circular 460, Publications of the National Bureau of Standards, 1901 to June 1947 (\$1.25), and the Supplement to National Bureau of Standards Circular 460, July 1947 to June 1957 (\$1.50), and Miscellaneous Publication 240, July 1957 to June 1960 (Includes Titles of Papers Published in Outside Journals 1950 to 1959) (\$2.25); available from the Superintendent of Documents, Government Printing Office, Washington 25, D.C. 
UNITED STATES DEPARTMENT OF COMMERCE - Luther H. Hodges, Secretary NATIONAL BUREAU OF STANDARDS - A. V. Astin, Director

\title{
Testing of Metal Volumetric Standards
}

\author{
J. C. Hughes and B. C. Keysar
}

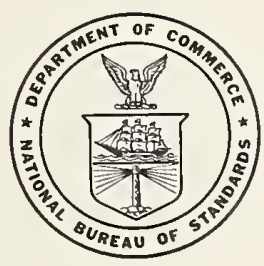

National Bureau of Standards Monograph 62 Issued April 1, 1963 
Library of Congress Catalog Card Number: 63-60025 


\section{Foreword}

This Monograph is intended primarily as a guide in the purchase and use of metal volumetric standards by weights and measures officials, by oil, gas, and pipeline companies, and by others who measure fluid products by volume.

The measures described herein are used principally as reference standards in the calibration of working standards. For this reason, specifications and tolerances have been established to insure that standards purchased are of suitable quality.

The courtesy of equipinent manufacturers who have supplied photographic material and drawings is greatly appreciated. 


\section{Contents}

Foreword

1. Introduction

1.1. Purpose

1.2. Organization $\ldots$

1.3. Scope

2. Liquid measures

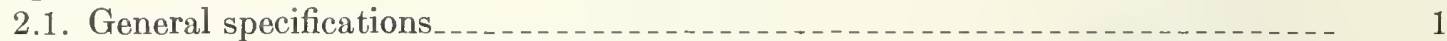

2.2. "Slicker plate" liquid measures _._._.

2.3. Graduated-neck liquid measures $\ldots \ldots \ldots$

2.4. Other liquid measures........ 5

3. Gas measures $\ldots \ldots \ldots$

3.1. General specifications__.

3.2. Immersion bottle $\ldots$

3.3. Portable cubic-foot (Stillman) standard $\ldots \ldots \ldots \ldots \ldots$

3.4. One-tenth cubic-foot bottle

4. Dry measures

5. Directions for submitting apparatus for test

5.1. Application for test $\ldots \ldots$

5.2. Shipping directions

5.3. Damage to apparatus

5.4. Address

5.5. Remittances

6. References

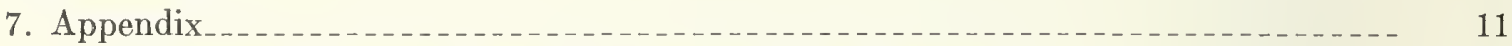

7.1. Change in capacity caused by change of temperature

7.2. Correction for difference in temperature

7.3. Correction for difference in thermal expansion of measures _ _ 


\title{
Testing of Metal Volumetric Standards
}

\author{
J. C. Hughes and B. G. Keysar
}

\begin{abstract}
The National Bureau of Standards has for many years calibrated and certified metal measures which are used as standards by weights and measures officials and others in the calibration of instruments for measuring the volumes of fluids. No complete specifications or tolerances for these standards have ever been published, however, nor have standardized procedures for the calibration and use of the liquid measures been available.

The information contained in this Monograph should assist in the purchase of quality instruments and the proper use of the standards in calibrating other measures for liquids and gases.
\end{abstract}

\section{Introduction}

\subsection{Purpose}

The specifications and tolerances contained in this Monograph should be of assistance to purchasers of metal capacity standards. The information on methods of calibration and use of these measures should prove valuable to weights and measures officials and those persons in industry who are concerned with measurements of volumes of fluids.

\subsection{Organization}

Although some repetition may result, it is believed that the separate and complete treatment of each type of measure will be more convenient to those who use this publication as a reference.

\subsection{Scope}

It is recognized that some types of metal capacity measures will not be covered by this publi- cation; however, it has been deemed advisable to provide specifications and tolerances for only those types which the National Bureau of Standards is called upon to calibrate. The principles involved in the design, calibration, and use of these basic standards are generally applicable to all types of metal capacity measures.

Measures submitted to the Bureau for certification should conform with the specifications contained herein; however, certificates may be issued to state agencies when required by state law whether or not the item complies in all respects with these specifications, if it is apparent that the item will perform its designed function.

The Bureau does not desire that the specifications contained herein work a hardship on the owner of costly equipment. Therefore, any metal capacity standard which has been previously certified will be accepted for recalibration as long as it is in good condition.

\section{Liquid Measures}

\subsection{General Specifications}

\section{a. Units of Capacity}

The great majority of metal liquid measures used in this country are in units of a gallon, which is defined as 231 in. $^{3}$ Metal measures are made in sizes as small as 1 gill, or 4 fluid ounces. Other units used are listed below with their equivalents.

$$
\begin{aligned}
& 1 \text { liquid pint }=4 \text { gills } \\
& 1 \text { liquid quart }=2 \text { liquid pints } \\
& 1 \text { gallon }=4 \text { liquid quarts } \\
& 1 \text { liter } \quad=1.05672 \text { liquid quarts } \\
& =61.0254 \text { cubic inches }
\end{aligned}
$$

\section{b. Standard Temperature}

Metal capacity measures are usually standardized at $60^{\circ} \mathrm{F}$ for use in the oil industry or at $68^{\circ} \mathrm{F}$ $\left(20^{\circ} \mathrm{C}\right)$ for milk and other food products.

\section{c. Design and Workmanship}

The cross section of any metal capacity standard must be circular, and the shape must permit complete emptying and draining. When a bottom drain extends outward from the center of a standard, it must slope at least 5 deg.

Instruments having a base must stand solidly on a level surface. If provided with a bail handle, a measure must hang with its axis vertical. The inside surface must be corrosion resistant, and all inside seams must be smoothly filled with metal to eliminate pockets where air or liquid may be trapped when the measure is used.

All measures must be sufficiently strong and rigid to prevent distortion of the vessel when full of liquid. Reinforcing bands, properly used, will eliminate the necessity for excessively heavy construction.

Valves must operate freely and positively, and there shall be no leakage from seams or fittings. 
Adjustable legs must be capable of easy operation when the measure is filled.

A capacity measure must be completely assembled before calibration or before shipment to the National Bureau of Standards. Anything which will extend through the wall must be in place. Volume-adjusting plugs must have provision for sealing.

The possibility of making certain types of liquid measures of materials other than metal has been under study. Nothing in these specifications is intended to preclude the use of other suitable materials, provided measures made of such materials conform with applicable parts of these specifications.

\section{2. "Slicker Plate" Liquid Measures}

\section{a. Design}

The most accurate metal measures for liquids are those in which the capacity is limited by a glass plate, commonly called a "slicker plate," which is slid into place on top of the measure. The top edge of the measure must be carefully machined so that there will be no leakage between the metal edge and the glass plate.

Cylindrical measures of this type have been used for many years; but the conical shape with a smaller top, because of its improved handling ease, is rapidly replacing the older and heavier cylindrical shape. The conical design, illustrated in figure 1, is used almost exclusively for measures of 1 gill to 1 gal. The 5-gal stainless steel small-

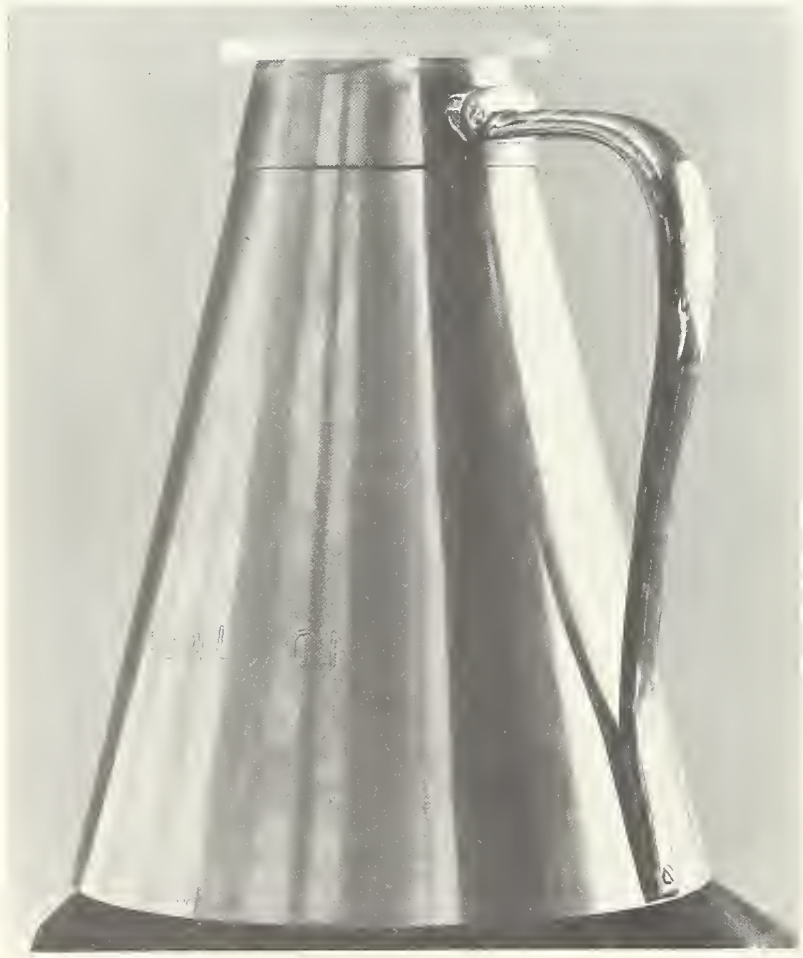

Figure 1. Conical measure. neck measure illustrated in figure 2 has proved very satisfactory as a standard for calibrating measures used in the field.

Slicker-plate measures larger than 1 gal are usually made with a bottom drain and a plug valve. Those of 1 gal or less can be manipulated without difficulty by means of the handle provided.

\section{b. Special Requirements}

The bottom of a conical measure, which has a relatively large area, should be designed so that it will resist denting or displacement in use. Final adjustments of the capacity should not be made by adding an excess of soft metal to the inside.

The inside diameter of the top opening should not be less than 1 in. for any size.

The nominal capacity of a slicker-plate measure shall be prominently engraved on the outside wall. If in units of a pint or a quart, the word "liquid" or the abbreviation "liq" shall be included in the inscription. The manufacturer's name or trademark and a serial number should be shown less conspicuously.

\section{c. Capacity Tolerances}

National Bureau of Standards certificates will be issued to cover the calibration of slicker-plate

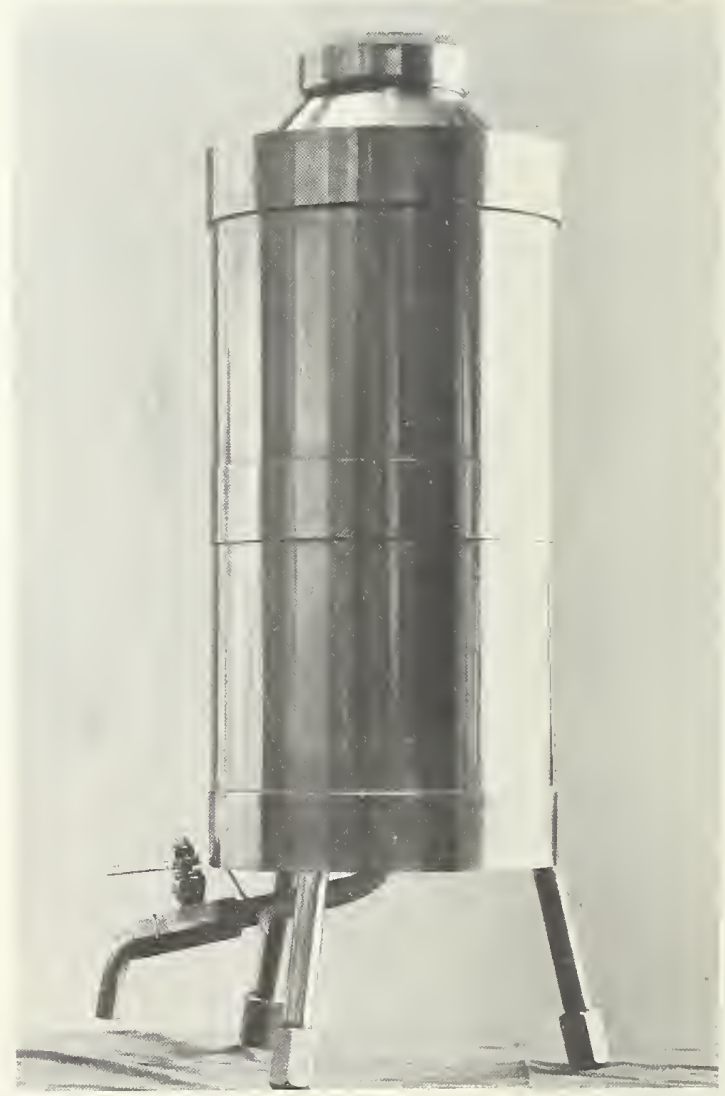

FiguRE 2, 5-gallon "slicker plate" measure. 
capacity standards when the corrections to the indicated capacities are not greater than the tolerances listed below. These tolerances represent the maximum errors that may be disregarded in normal use. When the corrections exceed the tolerances, but are not more than twice the tolerances, the results will be given on a Report form.

\begin{tabular}{|c|c|}
\hline Capacity & Tolerance \\
\hline \multicolumn{2}{|l|}{ Customary units } \\
\hline $\begin{array}{l}\text { Less than } 1 \text { pint } \\
1 \text { pint or larger }\end{array}$ & $\begin{array}{l}1 \text { part in } 1000 \\
1 \text { part in } 2000\end{array}$ \\
\hline \multicolumn{2}{|l|}{ Metric units } \\
\hline $\begin{array}{l}\text { Less than } 5 \text { deciliters } \\
5 \text { deciliters or larger }\end{array}$ & $\begin{array}{l}1 \text { part in } 1000 \\
1 \text { part in } 2000\end{array}$ \\
\hline
\end{tabular}

\section{d. Calibration and Use}

At the National Bureau of Standards, slickerplate measures are usually calibrated by weighing. After cleaning with an organic solvent, the measure is filled with distilled water until the water level is slightly below the top edge of the measure, and a thermometer inserted to determine the temperature. After removal of the thermometer, more water is added to raise the level above the top of the measure, and the glass slicker plate is pushed from one side across the top edge of the measure until the plate covers the opening completely. The excess of water is thus cut off and the measure should then be completely full. There should be no air bubble beneath the slicker plate; if one is present more water must be added.

All water on the outside of the measure and the exposed surfaces of the slicker plate is then removed with absorbent paper, and the filled measure is placed on the pan of a balance of adequate capacity. The tare is adjusted until the balance is in equilibrium. The measure is removed from the balance and emptied (in the case of a measure without a drain) by tipping until its axis is approximately horizontal and then carefully sliding the slicker plate upward to allow the water to flow out. The plate is slid completely off as soon as convenient, and after the main outflow has ceased the measure is held in a nearly inverted position and allowed to drain for 10 sec. It is then righted, the slicker plate replaced, and the measure returned to the balance pan. The weight which must be added to the same pan to restore equilibrium is the apparent weight of the water delivered by the measure.

The weight of water delivered is converted to volume by means of prepared tables which include corrections for temperature, atmospheric pressure, and humidity.
A slicker-plate measure having a bottom drain is emptied by moving the plate just far enough to allow air to enter the measure when the valve is opened, sliding it completely off alter flow has started. 'The drainage time for measures of this type is 30 sec.

If provided with means of adjustment, a slicker-plate measure will be sealed after calibration. An identifying number is applied by the National Bureau of Standards, and the actual volume delivered is reported as indicated in section 2.2.c.

In using a slicker-plate standard to calibrate another measure, it is filled as described in the method of calibration. It is not necessary to dry the outside so completely; however, it inust be sufficiently dry that no water will run off into the measure being calibrated. The standard is emptied as described in the calibration method.

\subsection{Graduated-Neck Liquid Measures}

\section{a. Design}

These measures are made in a wide range of capacities, from a quart or less to thousands of gallons. They have a relatively small neck on which is mounted a gage glass and a graduated scale. A typical measure is shown in figure 3.

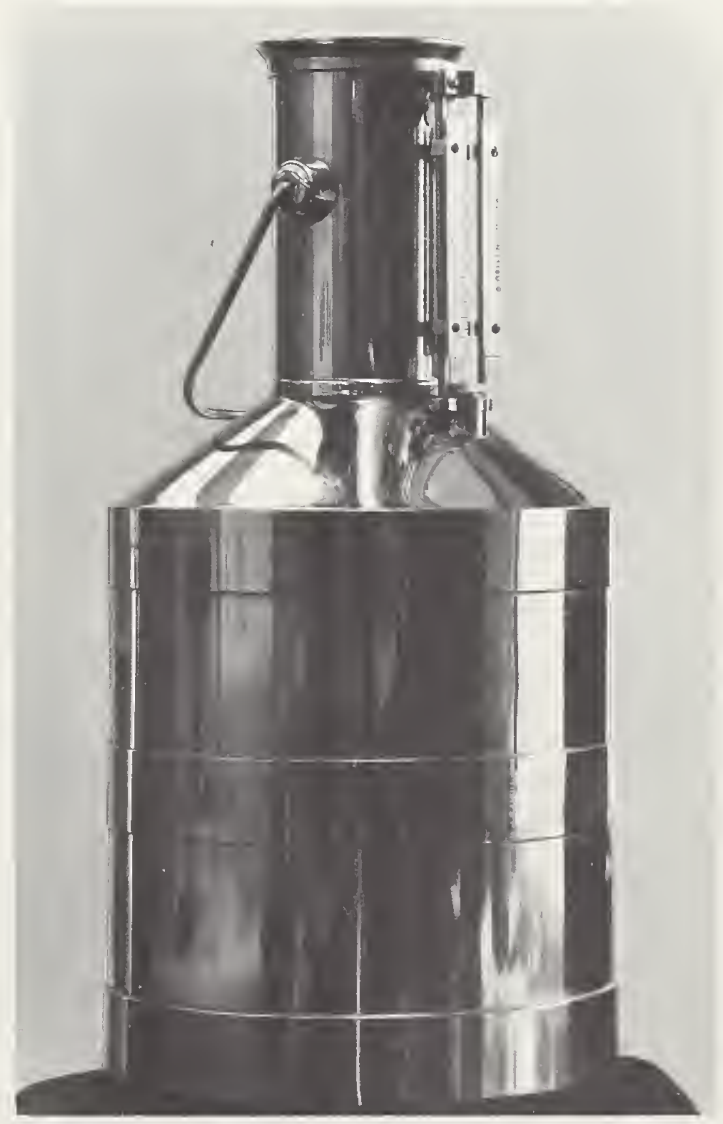

Figure 3. Graduated-neck measure. 
Measures of 1-gal to 10-gal capacity are usually made with a closed bottom and equipped with a bail or other form of handle for lifting and emptying. Measures of more than 10-gal capacity are usually made with a bottom drain and a valve. The larger measures are often equipped with adjustable legs for leveling.

\section{b. Special Requirements}

A bail handle should be attached to the neck rather than to the conical part of the body, to minimize any possibility of distortion.

The bottom should be designed so as to resist distortion when filled and to provide protection against damage in use.

The gage glass should be of clear glass tubing, free of any irregularities or defects which would distort the appearance of the liquid surface, and having an inside diameter of approximately $1 / 2$ in. If plastic tubing is used, it should be resistant to the chemical action of petroleum products. The mounting should be designed so that it will not interfere with brush cleaning of the inside of the tube. The bottom mounting of the gage glass should be made leakproof without the use of cement; that is, replacement of the glass tube should present no difficulties.

A scale of corrosion-resistant metal should be mounted approximately on a tangent to the front of the gage glass. It should not be more than $1 / 4$ in. from the gage glass. In most cases, the nominal capacity is designated by a zero line near the center of the scale, with at least 15 graduations above and 15 below the zero line. In special-purpose provers, such as those for high-vapor-pressure liquids, the design of the gage and scale may differ from that recommended above. The scale should be as near as possible to the recommended position, however. Numbering should be in whole units. The minimum distance between adjacent lines should be $3 / 16$ in. When two scales are used, the graduation lines representing equivalent volumes must lie in the same plane. Provision shall be made for finely adjusting, locking, and sealing the scale so that it cannot be moved.

The type of gage which is merely a window with a scale on the side is not considered suitable for use on a standard. The top edge of the meniscus appears as a distinct line on the window, while the bottom of the meniscus, which is the reading level, is barely discernible. For this reason, the Bureau does not accept for calibration measures equipped with this type of gage.

All measures should be level when the gage is read. Large measures (commonly called provers) which are to be used in a fixed location should be leveled when installed. Provers which may be moved must be equipped with a means of determining when they are level. The use of two small spirit levels, permanently mounted at right angles to each other, has proved satisfactory for this purpose. Leveling devices are not required on measures of 10 gal or less, as they are either placed on a level surface or suspended by the bail handle in use.

A bottom drain on a prover should be equipped with a quick-acting leakproof valve.

Each measure submitted to the Bureau for calibration must bear the maker's name or trademark and an identification or serial number.

\section{c. Capacity Tolerances}

Capacity

Tolerance

Customary units

Over 1 gallon (graduated neck)

1 gallon or less (graduated neck)

1 gallon (cylindrical-graduated in flo

1 quart (cylindrical-graduated in drams)

1 pint (cylindrical-graduated in drams) -

$1 / 2$ pint (cylindrical-graduated in drams)

1 part in 2000 1 part in 1000

$0.25 \mathrm{fl} \mathrm{oz}$

0.5 dram

0.5 dram

$0.5 \mathrm{dram}$

Metric units

Over 5 liters (graduated neck)

5 liters or less (graduated neck)

1 liter (cylindrical-graduated in $\mathrm{ml}$ )

1 part in 2000 1 part in 1000 $2 \mathrm{ml}$

\section{d. Calibration and Use}

At the National Bureau of Standards, graduated-neck measures of capacities up to and including 10 gal are calibrated by weighing. After cleaning with an organic solvent, the dry measure is placed on the pan of a suitable balance together with enough weights to equal or exceed the weight of the water which the measure will contain. Weights are added to the other pan until equilibrium is established. The measure is removed from the balance and filled with distilled water until the level is slightly above the zero mark on the scale. The water temperature is taken by lowering a thermometer approximately to the center of the measure, and the meniscus is set on the zero mark by withdrawing water in a suitable syringe. Before the final setting, the measure should be tilted toward the observer to wet the tube 1 or $2 \mathrm{~cm}$ above the zero mark.

When the water level is set or read in the gage, the line of sight must be horizontal. A convenient aid to a proper setting is a rectangular piece of white paper with a pencil line drawn through the center. The paper is slipped into place between the scale and adjusting rods and in back of the gage glass, the pencil line being alined exactly with the zero line on the scale.

When the water level has been adjusted to the zero mark, the measure is placed on the balance pan and equilibrium restored by removing weights from the pan bearing the filled measure. The total weight removed is the weight of water contained in the measure. If it is desired to determine what volume the measure will deliver, the 
water is poured out and the measure is allowed to drain in a nearly inverted position for 10 sec. It is again placed on the balance pan and weights added to the same pan until equilibrium is restored. The weight added is equal to the weight of the water delivered.

The weight of water contained in or delivered by the measure is converted to volume by means of prepared tables, which include corrections for temperature, atmospheric pressure, and humidity.

A measure of more than 10-gal capacity, commonly known as a "prover," is calibrated by the use of standards of appropriate size.

A graduated-neck measure may be calibrated either to contain or to deliver the nominal volume. A request for calibration should specify which is desired; when it does not, the measure will be calibrated "to deliver." A measure calibrated "to contain" must be completely emptied and dried before each filling, while a measure calibrated "to deliver" may be used to receive its nominal volume if it is filled and emptied, then drained for the prescribed time (10 sec for measures of 10 gal or less; $30 \mathrm{sec}$ for larger measures) before each measurement.

\subsection{Other Liquid Measures}

There are other metal liquid measures designed for special purposes, such as the meter provers described in API Standard 1101 [1]. ${ }^{1}$ Some are similar in design to the measures described in paragraph 2.3.a, while others differ greatly. Proving systems entirely closed to the atmosphere are essential for liquids of high vapor pressure. A widely used portable prover for liquefied petroleum gas meters is shown in figure 4 . It is built to withstand pressures up to about $300 \mathrm{lb} / \mathrm{in}^{2}$ The hose connected at the top permits vapor to pass freely between the prover and the supply

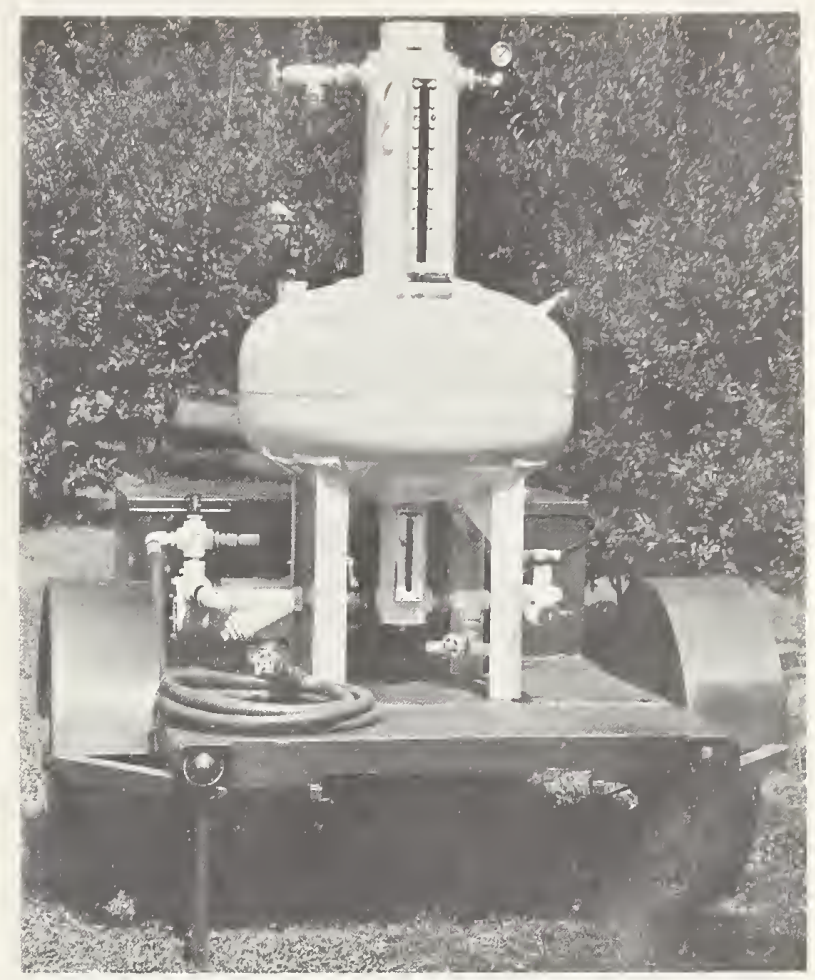

Figure 4. Liquefied petroleum gas meter prover.

tank, thus maintaining a constant pressure within the system while proving a meter.

When calibrating a closed prover under internal pressure, the drop in liquid level as pressure is applied is a combined result of tank expansion and decrease of liquid volume. To determine the change in tank volume, the change in gage reading must be reduced by the change in liquid volume. This change in liquid volume may be computed easily if the compressibility factor is known.

\section{Gas Measures}

\subsection{General Specifications}

\section{a. Units of Capacity}

Gas is measured almost exclusively in cubic feet in the United States. A few meters reading in liters are made here, principally for sale abroad. The relationship between these units is

$$
1 \text { cubic foot }=28.31605 \text { liters. }
$$

\section{b. Standard Temperature}

'The standard temperature for volume measurements of gas is $60^{\circ} \mathrm{F}$.

1 Figures in brackets indicate the literature references on page 11.

\section{c. Design and Workmanship}

Certain required features of design and workmanship are common to the three types of gasmeasuring standards.

(1) The cross section shall be circular, and the shape shall permit complete emptying and draining.

(2) The instruments must be sufficiently strong and rigid to resist denting or distortion.

(3) The materials used in their construction inust be corrosion resistant.

(4) All seams shall be smoothly filled with metal to eliminate crevices and pockets and to prevent leakage.

(5) Valves or cocks must operate smoothly and must not leak under maximum operating 
pressures. Three-way valves shall be marked to indicate the position of the plug openings.

(6) Volume-adjusting devices, whether indices, collars, or sleeves, must be provided with means for locking in place. The set screws provided for locking the adjusting sleeves on cubic-foot bottles, immersion and portable, should be drilled to receive sealing wires.

(7) Inscriptions shall include the maker's name or trademark, a serial number, and the nominal capacity.

\subsection{Immersion Bottle}

\section{a. Design}

The $1-\mathrm{ft}^{3}$ immersion bottle shown in figure 5 is used for calibrating gas-meter provers (gasometers). It has an opening about $2 \frac{1}{2}$ in. in diameter on the lower end, while the upper end is equipped with a gage glass with adjustable index, a 3-way control cock, and a hose fitting. A hose connects the bottle with the prover (gasometer), and lowering the bottle into the liquid (water or oil) to the gage index displaces $1 \mathrm{ft}^{3}$ of air at atmospheric pressure. After fabrication of the bottle, adjustment of the capacity is made by means of an adjustable collar on the open end.

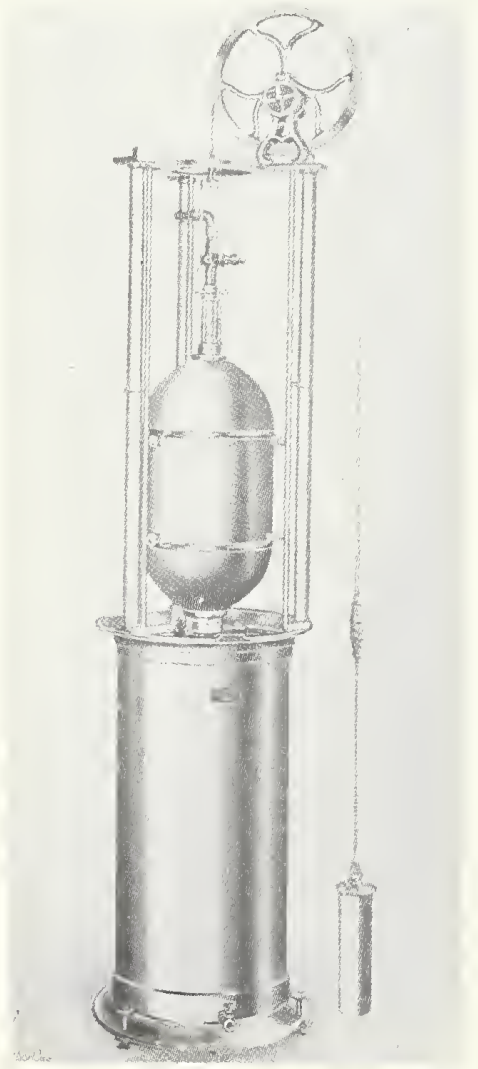

Figure 5. 1-ft $t^{3}$ immersion bottle.

\section{b. Special Requirements}

The bottom edge of the adjustable collar mentioned above must be smoothly finished, at right angles to the axis of the bottle. The collar must have provision for sealing gastight to the neck of the bottle. If this is accomplished by a packing ring above the collar, both ring and collar should be drilled in three or more places on the periphery so that spanner wrenches may be used to tighten or loosen the seal.

The gage glass shall be of clear glass tubing, sealed gastight within a gage body so designed that the liquid level may be easily observed. The gage marker or index shall be so constructed and mounted that it will resist bending or breaking. It should preferably be made of stainless steel.

\section{c. Capacity Tolerances}

The capacity of a $1-\mathrm{ft}^{3}$ immersion bottle is adjusted so that the volume of water delivered at $60^{\circ} \mathrm{F}$ between the gage index and the open end, allowing $3 \mathrm{~min}$ for emptying and an additional 3 min for draining, is $1.000 \mathrm{ft}^{3}$, with a tolerance of \pm 0.05 percent, or $\pm 0.0005 \mathrm{ft}^{3}$.

It is now the practice at the National Bureau of Standards to adjust these bottles so that the volume of water delivered under the above conditions is slightly more than $1.000 \mathrm{ft}^{3}$; for example, $1.0003 \mathrm{ft}^{3}$. If the bottle is used in oil instead of water, the volume of oil delivered will then be only slightly less than $1.000 \mathrm{ft}^{3}$; for example, $0.9997 \mathrm{ft}^{3}$. The best available data on the comparative drainage of water and the light oil recommended for use in gasometers indicate that, under the conditions outlined above, the volume of oil remaining on the inner wall of the bottle is approximately $0.0006 \mathrm{ft}^{3}$ more than that of water.

\section{d. Calibration and Use ${ }^{2}$}

The calibration described in section 3.2.c. is accomplished by weighing on a sensitive balance. The rate of emptying is controlled by an orifice plate attached to the open end.

For the standardization of a prover it is essential to have the temperature of the room constant throughout the test. If water is used in the prover (or bottle tank), evaporation from the wet sides of the bell (or bottle) as it is raised may cool the air within sufficiently to cause an appreciable error. There are two ways in which this trouble may be overcome. One is to saturate the air in the room with water vapor. The other method, which is recommended as preferable, is to use in place of the water a light clear oil of low vapor pressure.

The calibration of a prover by the cubic-foot bottle can be made either by measuring the air into the prover $1 \mathrm{ft}^{3}$ at a time until the prover is filled, or by filling the prover and measuring the air out $1 \mathrm{ft}^{3}$ at a time. There is no inherent reason why the two methods should not agree.

${ }^{2}$ Much of the material on the use of the cubic-foot standards is taken from NBS Cire. 309 [2]. 
Successive calibrations should agree within 0.2 percent.

The bottle and prover should be kept near each other for a long enough period before the test (preferably overnight) so that they will be at the same temperature.

To test bottle and connections for leaks, the counterweights of the prover are adjusted until the pressure in the prover is about $1 \mathrm{in}$. of water. The bottle is lowered into the tank and connected with the prover. The valves between bottle and prover are opened until the pressure in the system is the same as that in the prover. The prover valve is then closed and the setup allowed to stand for 5 or $10 \mathrm{~min}$. If the temperatures of the air and bottle do not change, the pressure, as indicated by the gage on the prover connection, should remain constant.

The prover bell can also be tested for leaks during this interval by raising it and noting its position. If the temperatures of the air and prover do not change, the bell should remain stationary.

(1) Bottling Out of the Prover. Bottling out of a prover with an immersion bottle may be done either at atmospheric pressure or at the usual prover pressure. The procedure for calibrating at the usual prover pressure will be described first.

After making sure that all connections are tight, and with the bell raised as high as possible without unsealing, the valve between prover and bottle is opened, making the pressure within the bottle the same as in the prover. The quantity of liquid in the bottle tank is then adjusted until the surface of the liquid within the gage glass of the bottle is in the plane of the gage mark. There may be some difficulty in making this adjustment because the surface of the liquid in the tank, outside the bottle, will be above the gage mark by an amount sufficient to balance the pressure of the prover. By manipulation of the prover slide valve the zero of the prover scale is now brought exactly opposite the pointer. The bottle is now raised steadily from the tank, thus drawing into it air from the prover. Since the test is being made at the usual prover pressure, the opening of the lower neck will still be submerged by an amount sufficient to I equal the pressure of the prover when the bottle is filled with air. It will be necessary, therefore, to raise the bottle very slowly when it is nearly filled with air and to stop the instant the first small bubble breaks out from the bottom of the bottle. If the work is done carefully, there is no need of losing more than one or two very small bubbles of air.

Now that a cubic foot of air has been removed from the prover, the prover valve is closed and the reading of the scale is noted. A small amount of air is then returned from the bottle to the prover so as to raise the $1-\mathrm{ft}$ mark of the prover scale above the index mark. The bottle is then submerged after opening its valve to the atmosphere. The prover bell is now adjusted so that the $1-\mathrm{ft}$ scale mark coincides with the pointer and another cubic foot of air may be bottled out.

If the test is made at atmospheric pressure the procedure will be substantially the same as that just described. The special precautions occasioned by the prover pressure will now be unnecessary. However, it would be advisable when raising the bottle from the tank not to unseal the bottom of the lower neck until after closing the valve between the prover and the bottle in order to guard against accidental shifting of the prover bell.

(2) Bottling Into the Prover. This method is the reverse of the precerling with the exception that it is practically necessary to use atmospheric pressure in the bottle and prover during the test. This merely requires that the counterweights of the prover be increased until the bell is just balanced.

\subsection{Portable Cubic-Foot (Stillman) Standard}

\section{a. Design}

A portable cubic-foot standard (also called a Stillman cubic-foot standard) is illustrated by figures 6 and 7 . The essential details of construction (shown by fig. 7) are as follows: the bell $a$ fits into the annular tank $b$, guided by the telescoping tubes $c$ and $d$ and the collars $e$ and $f$. Collar $e$ is threaded onto the inner tube $d$ and serves as both a guide ring and a stop to limit

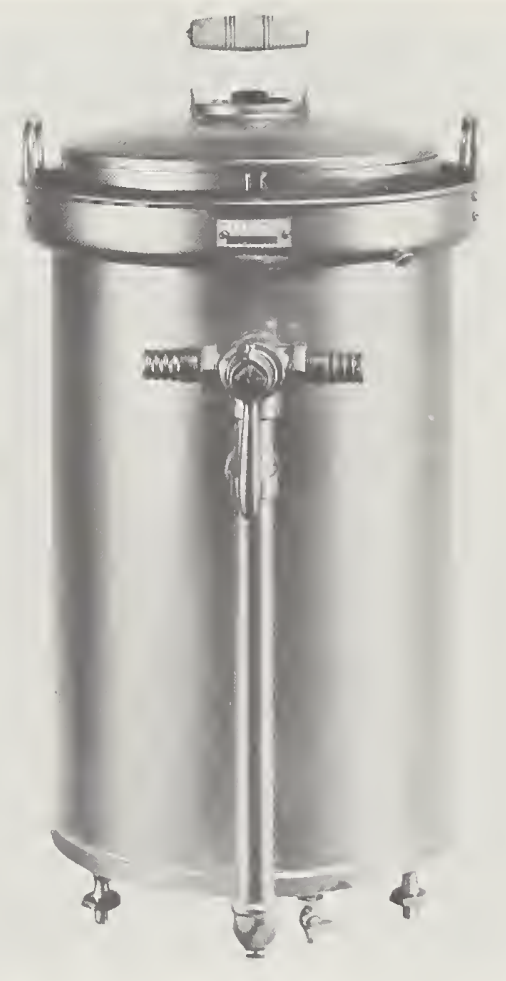

Figure 6. Portable 1 -ft $t^{3}$ standard.

(Courtesy of American Meter Company) 


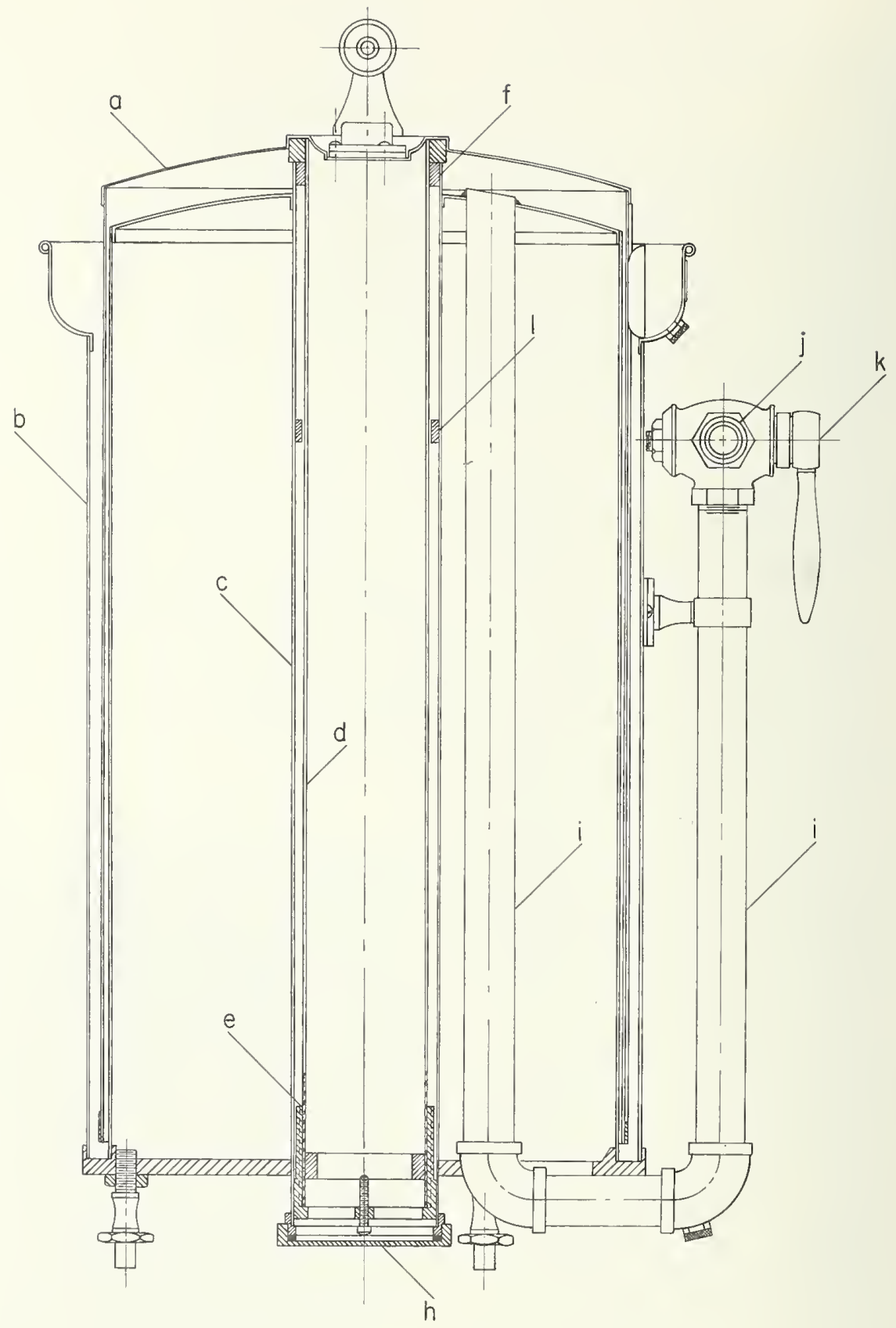

Figure 7. Diagram of portable 1-ft ${ }^{3}$ standard.

the upward travel of the bell. Collar $f$ and stop ring $l$ are fixed to the inside of the outer tube. By changing the position of collar $e$ on tube $d$ the height to which the bell may be raised is changed. It is by this means that the displacement of the bell is adjusted to exactly $1 \mathbf{f t}^{3}$. The cap $h$ forms a gastight seal. The tube $i$ serves as an inlet to or outlet from the interior of the bell. A flexible hose connecting this standard with a prover or other instrument is attached at $j$, and the flow of gas into or out of the standard is controlled by a 3 -way valve $k$.

Water or a light oil may be used as the sealing liquid in the annular $\operatorname{tank} b$; however, if water is used, this standard will be subject to the same disadvantages as were mentioned in the discussion of the immersion type of cubic-foot bottle, which may be overcome by the same methods as then suggested. The quantity of sealing liquid required is a little over 1 gal. 


\section{b. Special Requirements}

Portable cubic-foot standards are equipped with a circular type spirit level mounted on top of the bell. The level must be carefully mounted so that its indication is correct. The tank rests on three leveling screws.

The stop ring $l$ and collar $e$ (fig. 7) which limit travel of the bell must meet squarely. They must be free of solder or other foreign matter on the contact surfaces. This requirement applies also to the shoulder where tube $d$ is joined to the bell, and the collar $f$, which serve to limit the downward travel of the bell. The tank, bell, and guide tubes must be truly concentric in order that there will be no binding at any point and the bell will not depart from a level condition as it is raised.

A drain cock shall be provided at the bottom of the tank, while the inlet-outlet tube must have a drain hole fitted with a gastight plug. If there is a bleed hole in the flared ring at the top of the tank, this hole must also be fitted with a leakproof plug.

The bottom cap on the outer guide tube shall be fitted with a gasket which will provide a positive seal when tightened by hand.

The adjusting sleeve must be carefully machined so that it turns easily.

\section{c. Capacity Tolerance}

A certificate will be issued for a portable cubicfoot standard of the Stillman type if the error in the volume of air delivered at $60{ }^{\circ} \mathrm{F}$ by a full stroke of the bell does not exceed 0.05 percent or $0.0005 \mathrm{ft}^{3}$.

\section{d. Calibration and Use}

For adjusting a portable standard to receive or deliver $1 \mathrm{ft}^{3}$ of gas, an accurately adjusted immersion-type bottle is connected to the standard. The stroke of the bell is then so adjusted that, upon discharging $1 \mathrm{ft}^{3}$ of gas from the immersion bottle into the portable standard essentially no change of pressure takes place within the system. Actually a small change of pressure will result from the drainage of the sealing fluids, but this need be taken into account only for calibrations of the highest accuracy. Both the portable standard and the immersion bottle must, of course, be at the same temperature.

This standard may be operated at atmospheric pressure or slightly higher. In either case it is essential to have the pressure within the standard and apparatus under test the same at the end of the bell stroke as at the start.

The bell should be in the same position relative to the tank when at the bottom and top of its stroke. Current production models are equipped I with a device which allows vertical movement only.

The bell should rest tightly against the stops when at either the upper or lower position, but should not be allowed to strike either stop hard; the bell should be raised and lowered evenly and without undue force.

This portable standard has the important advantage of being very easily moved. If provided with a suitable case it may be shipped from place to place without danger of injury. The method of operation is very easy and rapid. When used to calibrate a meter prover the ordinary prover pressure may be used, a practice that is not always possible when using other types of cubic-foot bottles. The Bureau has found that it is possible to calibrate meter provers with this type of standard to practically the same degree of accuracy as is obtained when the older forms of cubic-foot bottles are employed.

\subsection{One-Tenth Cubic-Foot Bottle}

\section{a. Design}

The $1 / 10-\mathrm{ft}^{3}$ bottle illustrated by figures 8 and 9 is used principally for setting the water level in, or calibrating, small water-sealed rotating-drum meters (commonly called wet-test meters). It has gage glasses on top and bottom, fittings for hose of approximately $\frac{3}{8}$ in. i.d. on top and bottom, and a 3-way valve, or cock, on the top. The gages are provided with adjustable markers, or indices, to mark the capacity limits.

\section{b. Special Requirements}

The gage markers, or indices, are normally supported on a guide rod at one point only; therefore, they must be of rigid construction to prevent bending.

\section{c. Capacity Tolerances}

A certificate will be issued for a $1 / 10-\mathrm{ft}^{3}$ bottle if, with the gage markers set within the middle half of the exposed gage glass length, the bottle delivers $0.10000 \pm 0.00005 \mathrm{ft}^{3}$ at $60{ }^{\circ} \mathrm{F}$. The capacity is reported to $0.00001 \mathrm{ft}^{3}$.

\section{d. Calibration and Use}

Calibration of a fractional cubic-foot bottle is accomplished by weighing the water delivered. A stopcock is clamped to the lower hose fitting and the bottle filled from the bottom until the level is slightly above the upper gage index. A few blows on the bottle with the palm of the hand will displace air bubbles which may collect on the inside walls. The bottle is then clamped in a stand and water is drained out through the stopcock until the level is exactly at the upper index. Any excess water on the tip is touched off against the inside wall of the receiving vessel, which is then replaced with a weighing flask.

With the stopcock fully open, the water is discharged against the inner wall of the flask neck until the level in the bottle approaches the lower index. The discharge is slowed, and stopped when the level is exactly at the index. The rate of 


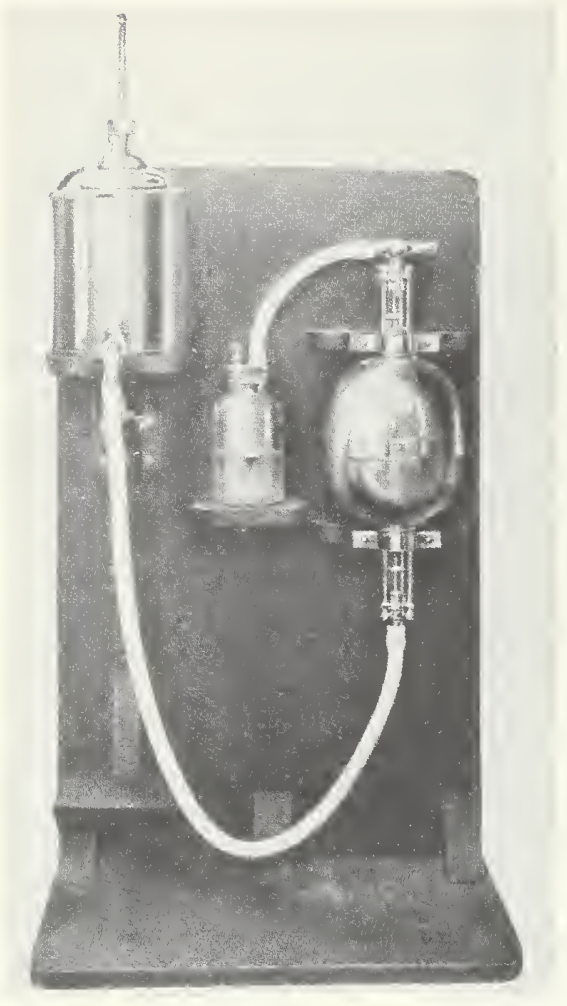

FIGURE 8. One-tenth $\mathrm{ft}^{3}$ bottle.

(Courtesy of American Meter Company)

outflow is controlled by the size of the opening in the tip so that the time of outflow is approximately equal to that required in use plus the 30 -sec drainage time prescribed in ASTM Standard Method D 1071 [3] (about 2 min). Any excess water at the stopcock tip is touched off against the inner wall of the flask, after which the flask is stoppered and weighed.

The method of using a $1 / 10-\mathrm{ft}^{3}$ bottle to calibrate a $1 / 10-\mathrm{ft}^{3}$ wet-test meter is described in detail in AS'TM Standard D 1071 [3].

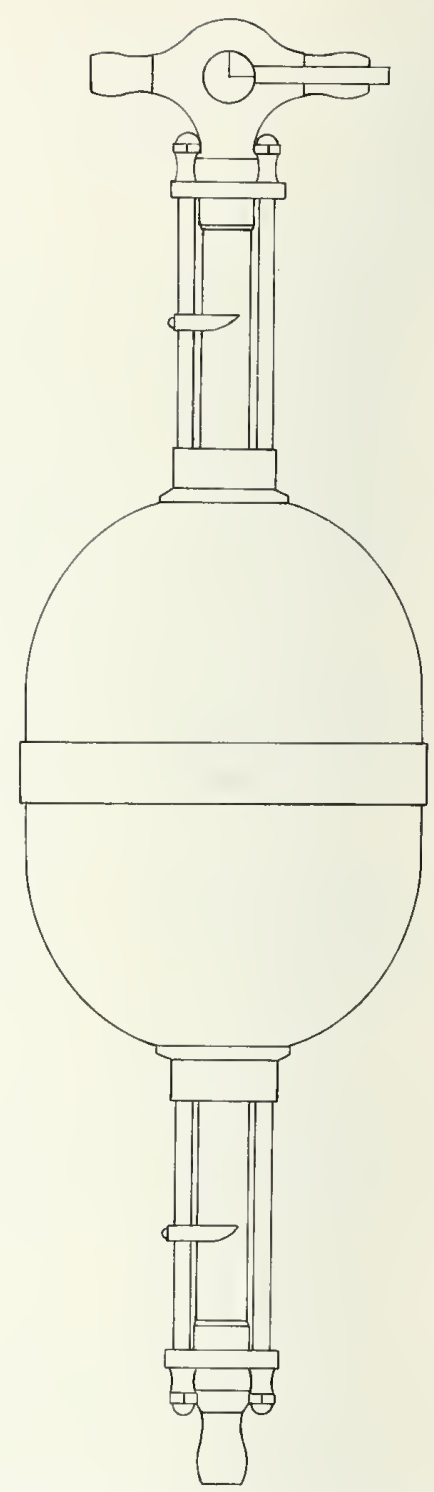

Figure 9. Diagram of $1 / 10 \mathrm{ft}^{3}$ bottle.

\section{Dry Measures}

The use of dry measures is prohibited by law in some jurisdictions. The sale of dry commodities by weight has become so prevalent that the use of dry measures is rare even where permitted. For completeness, however, there is presented here a brief discussion of standards of dry measure.

\subsection{Design}

Standards of dry measure are cylindrical in shape, with sizes ranging usually from $1 / 2 \mathrm{pt}$ to $1 / 2 \mathrm{bu}$. The capacity is defined by the top edge of the standard.

\subsection{Special Requirements}

Measures must be sufficiently strong and rigid to prevent distortion of the vessel when filled.

The top edge of a standard must be machined true, so that a watertight closure may be obtained with a glass "slicker plate."

The nominal capacity shall be prominently engraved on the outside wall. If in units of a pint or a quart, the word "dry" shall be included in the inscription. 'The manufacturer's name or trademark and a serial number should be shown less conspicuously. 


\subsection{Capacity Tolerance}

The capacity tolerance for standards of dry measure shall be 1 part in 1,000 .

\subsection{Calibration and Use}

The capacity of a dry measure is computed from the weight of water which it will contain, using a slicker plate to determine when it is filled exactly to the top. The use of these measures with dry commodities is described in NBS Handbook 45 [4].

\section{Directions for Submitting Apparatus for Test}

\subsection{Application for Test}

The request for test should be made in writing and should include a list of the apparatus, the method of calibration desired (to contain or to deliver), the standard temperature (if not marked on the apparatus), and the material of which the instruments are made, if known.

Representatives of state institutions entitled to tests free of charge must make application in writing for each test in order to avail themselves of the privilege.

Patrons should always examine apparatus carefully before submitting it for test to ascertain if it complies with the construction specifications, is free of dents and rust, does not leak, and is in good condition generally. Delay and cost of transportation on apparatus not entitled to verification will thus be avoided.

The Bureau does not sell volumetric apparatus. It may be purchased from manufacturers or jobbers and submitted for test. Purchasers of apparatus to be submitted to the Bureau for test should so specify to the dealer in order to avoid unnecessary delays and misunderstandings.

\subsection{Shipping Directions}

The apparatus should be securely packed in cases or packages which will not be broken in transportation and which may be used in returning the tested material to the owner.

Transportation charges are payable by the party requesting the test. The charges for shipment to the Bureau must be prepaid; and, unless otherwise arranged, articles will be returned or forwarded by express collect.

After the material is received at the Bureau, the shipper will be notified of the test number assigned. This number should be mentioned in any correspondence pertaining to the test.

When submitting immersion bottles for calibration, do not include the tank. It is not used in the calibration, and the crating and shipping would involve a considerable expense.

\subsection{Damage to Apparatus}

In spite of reasonable care in handling, it is possible that damage may occur during testing. There is no legal way in which the Bureau can make reimbursement for damage of this kind. It is therefore a matter of necessity, and not of choice, that the Bureau makes those who send apparatus for test assume all the risks involved.

\subsection{Address}

Articles and communications should be addressed, National Bureau of Standards, Washington $25, \mathrm{D} . \mathrm{C}$.

\subsection{Remittances}

Payment of test fee should be made promptly upon receipt of bill. Remittances may be made by money order or check drawn to the order of the "National Bureau of Standards."

Copies of the current Test Fee Schedules may be obtained from the Bureau upon request.

\section{References}

[1] API Standard 1101, American Petroleum Institute, New York, N.Y. (1960).

[2] NBS Circ. 309 (1926). Gas ineasuring instruments.
[3] ASTM Standard D 1071, Amer. Soc. for Testing and Materials, Philadelphia, $\mathrm{Pa}$.

[4] NBS Handb. 45, p. 198 (1951). Testing of measuring equipment.

\section{Appendix}

\subsection{Change in Capacity Caused by Change of Temperature}

If the capacity of a measure at any temperature, for example $60^{\circ} \mathrm{F}$, is known, the capacity at another temperature may be determined by the use of the following formula:

$$
V_{t}=V_{60}[1+\alpha(t-60)]
$$

where

$$
\begin{aligned}
& V_{t}=\text { capacity at } t^{\circ} \mathrm{F}, \\
& V_{60}=\text { capacity at } 60^{\circ} \mathrm{F}, \\
& \alpha=\text { coefficient of cubical expansion } \\
& \text { of the material of which the } \\
& \text { measure is made, per degree } \\
& \text { F. }
\end{aligned}
$$


Average coefficients (per ${ }^{\circ} \mathrm{F}$ ) for the metals most widely used in capacity standards are:
Brass
0.000030
Copper
.000028
Low carbon steel
.000018
$18-8$ stainless steel
.000028

\subsection{Correction for Difference in Temperature}

If the temperature of the water in the standard differs from that of the water in the measure being calibrated, a correction must be applied to bring the volumes of water to the same temperature basis.

A table for this purpose has been incorporated (table I) in API Standard 1101 [1]. Lacking such a table, factors for the adjustment of water volumes to a common temperature may be derived from the density values. Water density tables are available from several sources including physics and chemistry handbooks.

Any correction to the water volume is partly offset by the volume change in the metal measures. (The temperature of a measure is assumed to be the same as that of the water contained.) To adjust the capacity of one measure to the capacity it would have at the temperature of the other, a modification of formula (1) may be used.

$$
\text { Correction }=V \alpha\left(t-t_{1}\right)
$$

where

$V=$ measured volume

$\alpha=$ coefficient of cubical expansion of the measure whose volume is being adjusted.

$t-t_{1}=$ temperature difference between measures.

As an example of the correction for a difference in temperature, let us assume that the average temperature of the water in a standard graduated to deliver 100 gallons at $60^{\circ} \mathrm{F}$ was $74^{\circ} \mathrm{F}$, but after being emptied into the prover it was measured at $76^{\circ} \mathrm{F}$. Both measures are of mild (low carbon) steel.

The change in the volume of water from 74 to $76^{\circ}$ may be computed from the formula

$$
\begin{aligned}
V_{76} & =V_{74} \times \frac{\text { density of water at } 74^{\circ}}{\text { density of water at } 76^{\circ}} \\
& =100 \mathrm{gal} \times \frac{0.99748}{0.99721} \\
& =100.027 \text { gal. }
\end{aligned}
$$

The change is $100.027-100.000$, or 0.027 gal.

While the volume of water was increasing, the capacity of the prover also increased by an amount represented by formula (2), or

$$
100 \times 0.000018 \times 2=0.0036 \mathrm{gal} .
$$

The net correction for the temperature difference, therefore, is $0.027-0.0036$ or $0.0234 \mathrm{gal}$. Because the water in the prover is warmer than when in the standard, the level in the gage will be higher than it would be if the temperatures had remained the same, and must be lowered by 0.0234 gal before adjusting the scale to the water level.

If the two measures are made of materials having the same thermal expansion coefficient, no further correction is necessary, since the standard is correct at $60^{\circ} \mathrm{F}$.

\subsection{Correction for Difference in Thermal Ex- pansion of Measures}

If a standard is being used to calibrate a measure made of material having a different thermal expansion coefficient, and the temperature is other than the standard temperature (usually $60^{\circ} \mathrm{F}$ ) a correction must be applied to account for the difference in volume change of the two instruments. The correction may be represented by the following equation:

$$
C=V(t-60)\left(\alpha_{1}-\alpha_{2}\right)
$$

where

$$
\begin{aligned}
C & =\text { correction } \\
V & =\text { measured volume } \\
t & =\text { temperature of observations }\left({ }^{\circ} \mathrm{F}\right) \\
\alpha_{1} & =\text { cubical coefficient of thermal expansion } \\
& \text { of metal in standard } \\
\alpha_{2} & =\text { cubical coefficient of thermal expansion } \\
& \text { of metal in measure being calibrated. }
\end{aligned}
$$

For example, suppose that a 100-gal prover made of low-carbon steel is being calibrated with a 50-gal standard made of 18-8 stainless steel. The average temperature (measured in the water when the instruments are full) is $75^{\circ} \mathrm{F}$. The correction would be:

$$
\begin{aligned}
C & =100(75-60)(0.000028-0.000018) \\
& =0.015 \mathrm{gal} \text { or } 3.465 \text { in. }^{3}
\end{aligned}
$$

The standard, having a larger expansion coefficient, will, when filled and emptied twice into the prover, fill the prover to a higher level by 3.465 in. ${ }^{3}$ than it would if both measures were at the standard temperature of $60^{\circ} \mathrm{F}$. If the water level in the prover were lowered by 3.465 in. $^{3}$ and the zero line on the scale adjusted to that level, the prover would be correct at $60^{\circ} \mathrm{F}$.

When working at a temperature below $60^{\circ} \mathrm{F}$, the scale should be adjusted upward when other conditions are as in the preceding example. At $50{ }^{\circ} \mathrm{F}$ the correction would be $100 \times 10 \times 0.00001$ or $0.010 \mathrm{gal}\left(2.31 \mathrm{in}^{3}\right)$. If $2.31 \mathrm{in.}^{3}$ of water were added to the prover and the zero line on the scale adjusted to that level, the prover would be correct at $60^{\circ} \mathrm{F}$. 
U.S. DEPARTMENT OF COMMERCE

Luther H. Hodges, Secretary

NATIONAL BUREAU OF STANDARDS

A. V. Astin, Director

\section{THE NATIONAL BUREAU OF STANDARDS}

The scope of activities of the National Bureau of Standards at its major laboratories in Washington, D.C., and Boulder, Colorado, is suggested in the following listing of the divisions and sections engaged in technical work. In gen eral, each section carries out specialized research, development, and engineering in the field indicated by its title. A brief description of the activities, and of the resultant publications, appears on the inside of the front cover.

\section{WASHINGTON, D.C.}

Electricity. Resistance and Reactance. Electrochemistry. Electrical Instruments. Magnetic Measurements. Dielectrics. High Voltage. Absolute Electrical Measurements.

Metrology. Photometry and Colorimetry. Refractometry. Photographic Research. Length. Engineering Metrology. Mass and Scale. Volumetry and Densimetry.

Heat. Temperature Physics. Heat Measurements. Cryogenic Physics. Equation of State. Statistical Physics. Radiation Physics. X-ray. Radioactivity. Radiation Theory. High Energy Radiation. Radiological Equipment. Nucleonic Instrumentation. Neutron Physics.

Analytical and Inorganic Chemistry. Pure Substances. Spectrochemistry. Solution Chemistry. Standard Reference Materials. Applied Analytical Research. Crystal Chemistry.

Mechanics. Sound. Pressure and Vacuum. Fluid Mechanics. Engineering Mechanics. Rheology. Combustion Controls.

Polymers. Macromolecules: Snythesis and Structure. Polymer Chemistry. Polymer Physics. Polymer Characterization. Polymer Evaluation and Testing. Applied Polymer Standards and Research. Dental Research.

Metallurgy, Engineering Metallurgy. Microscopy and Diffraction. Metal Reactions. Metal Physics. Electrolysis and Metal Deposition.

Inorganic Solids. Engineering Ceramics. Glass. Solid State Chemistry. Crystal Growth. Physical Properties • Crystallography.

Building Research. Structural Engineering. Fire Research. Mechanical Systems. Organic Building Materials. Codes and Safety Standards. Heat Transfer. Inorganic Building Materials. Metallic Building Materials.

Applied Mathematics. Numerical Analysis. Computation. Statistical Engineering. Mathematical Physics. Operations Research.

Data Processing Systems. Components and Techniques. Computer Technology. Measurements Automation. Engineering Applications. Systems Analysis.

Atomic Physics. Spectroscopy. Infrared Spectroscopy. Far Ultraviolet Physics. Solid State Physics. Electron Physics. Atomic Physics. Plasma Spectroscopy.

Instrumentation. Engineering Electronics. Electron Devices. Electronic Instrumentation. Mechanical Instruments. Basic Instrumentation.

Physical Chemistry. Thermochemistry. Surface Chemistry. Organic Chemistry. Molecular Spectroscopy. Elementary Processes. Mass Spectrometry. Photochemistry and Radiation Chemistry.

Office of Weights and Measures.

\section{BOULDER, COLO.}

Cryogenic Engineering Laboratory. Cryogenic Equipment. Cryogenic Processes. Properties of Materials. Cryogenic Technical Services.

\section{CENTRAL RADIO PROPAGATION LABORATORY}

Ionosphere Research and Propagation. Low Frequency and Very Low Frequency Research. Ionosphere Research. Prediction Services. Sun-Earth Relationships. Field Engineering. Radio Warning Services. Vertical Soundings Research.

Radio Propagation Engineering. Data Reduction Instrumentation. Radio Noise. Tropospheric Measurements. Tropospheric Analysis. Propagation-Terrain Effects. Radio-Meteorology. Lower Atmosphere Physics.

Radio Systems. Applied Electromagnetic Theory. High Frequency and Very High Frequency Research. Frequency Utilization. Modulation Research. Antenna Research. Radiodetermination.

Upper Atmosphere and Space Physics. Upper Atmosphere and Plasma Physics. High Latitude Ionosphere Physics. Ionosphere and Exosphere Scatter. Airglow and Aurora. Ionospheric Radio Astronomy.

\section{RADIO STANDARDS LABORATORY}

Radio Physics. Radio Broadcast Service. Radio and Microwave Materials. Atomic Frequency and Time-Interval Standards. Radio Plasma. Millimeter-Wave Research.

Circuit Standards. High Frequency Electrical Standards. High Frequency Calibration Services. High Frequency Impedance Standards. Microwave Calibration Services. Microwave Circuit Standards. Low Frequency Calibration Services. 
